\title{
COMMUNITY-BASED HEALTH-PROFESSIONS INTERPROFESSIONAL EDUCATION: A COLLABORATIVE AND SUSTAINABLE MODEL
}

\author{
Tri Nur Kristina*, Sudaryanto*, Fatikhu Yatuni Asmara*, Nuryanto*, Firman Wirakusumah**, Yoni Syukriani** \\ * Fakultas Kedokteran Universitas Diponegoro, Semarang - INDONESIA \\ ** Fakultas Kedokteran Universitas Padjajaran, Bandung - INDONESIA
}

\begin{abstract}
Background: Community health problems should be solved comprehensively dan collaboratively by involving several health professionals. Combination of Community-based education (CBE) with Interprofessional education (IPE) might contribute in the management of community health problems and give experiences of health team collaboration for health professions students.
\end{abstract}

Method: This was a preeliminary study to develop and to validate Model CBE-IPE. Research was done in the Faculty of Medicine Diponegoro University, Semarang involving 3 study programs i.e. Medicine, Nursing, and Nutrition. Research method was qualitative study by using document analyses to develop draft model followed by Focus Group Discussion (FGD) to validate the model.

Results: Based on comparability of the curriculum and acquired competencies, the model can only be sufficient if implemented for students in $6^{\text {th }}$ semester. The model has been agreed to be implemented with several input and suggestions. Small group of students should work together to assess health problems in 1-2 family, to implement intervention, to monitor and evaluate their intervention, and to report their work. Assessment including activity, peer assessment, family evaluation, ability of presentation and discussion, and report writing. Perceptions of students, instructurs, and community member will be asked after implementation to evaluate the program.

Conclusion: Model of CBE-IPE suggested to be implemented for students who have sufficient competencies to be applicated in the community. Review and further validation of this model is still needed after implementation.

Keywords: CBE, IPE, health-profession, collaboration, community

\begin{abstract}
ABSTRAK
Latar belakang: Penanganan masalah kesehatan di masyarakat memerlukan pendekatan yang komprehensif dan bersifat kolaborasi antar profesi kesehatan. Diharapkan Model Pembelajaran Berbasis Komunitas (PBK) yang dikombinasikan dengan interprofessional education (IPE) dapat berkontribusi untuk mengatasi permasalahan kesehatan masyarakat sekaligus memberikan pengalaman bagi mahasiswa profesi kesehatan dalam berkolaborasi.

Metode: Merupakan penelitian awal untuk mengembangkan dan memvalidasi model PBK-IPE. Penelitian dilaksanakan di FK Undip, Semarang dengan melibatkan 3 prodi: S1 Kedokteran, S1 Keperawatan, dan S1 Gizi. Desain penelitian adalah kualitatif dengan menggunakan analisis dokumen untuk menghasilkan draft model PBK-IPE, dilanjutkan dengan Diskusi Kelompok Terfokus (DKT) untuk memvalidasi model.

Hasil: Ditinjau dari aspek keselarasan kurikulum dan kecukupan kompetensi yang telah didapat, model PBK-IPE di FK Undip hanya sesuai bila dilaksanakan oleh mahasiswa semester 6. Model telah disepakati untuk diimplementasikan dengan beberapa masukan dan saran. Kelompok kecil mahasiswa akan bekerja
\end{abstract}

contact: t_nurkristina@yahoo.com 
sama dalam mengases permasalahan kesehatan dalam 1-2 keluarga, melakukan intervensi, memonitor serta mengevaluasi hasil intervensi dan mempresentasikan laporannya. Asesmen meliputi keaktifan, penilaian teman, penilaian keluarga, kemampuan presentasi dan berdiskusi, serta laporan tertulis. Persepsi mahasiswa, instruktur, dan anggota masyarakat akan diminta setelah program diimplementasikan.

Kesimpulan: Model PBK-IPE disarankan untuk diimplementasikan bagi mahasiswa yang telah memiliki kompetensi yang cukup untuk diaplikasikan di masyarakat. Kajian dan validasi lanjut terhadap model masih perlu dilakukan setelah diimplementasikan.

Kata kunci: PBK, IPE, profesi kesehatan, kolaborasi, masyarakat

\section{PENDAHULUAN}

Permasalahan kesehatan di masyarakat sangat kompleks dan bervariasi sehingga membutuhkan penatalaksanaan yang bersifat komprehensif. Sebagian besar permasalahan kesehatan di masyarakat berusaha untuk ditanggulangi oleh pemerintah (Kementerian Kesehatan) dengan berbagai program kesehatan yang bersifat nasional. Meskipun demikian hasilnya masih belum memuaskan. Banyak permasalahan kesehatan yang masih memprihatinkan, misalnya kesehatan ibu dan anak, penyakit-penyakit tropis, penyakit akibat lingkungan, kesehatan reproduksi remaja, dan lansia. ${ }^{1}$

Fakultas Kedokteran seharusnya ikut berkontribusi dalam menanggulangi masalah kesehatan di masyarakat, terutama yang berlokasi di wilayah sekitar institusi tersebut maupun wilayah lainnya. Metode pembelajaran di mana mahasiswa berada di masyarakat untuk membantu mengatasi permasalahan (terutama kesehatan) di wilayah tersebut dikenal dengan istilah community-based education (CBE) atau Pembelajaran Berbasis Komunitas (PBK). Fakultas Kedokteran harus menyadari fungsinya yang tidak hanya sekedar memberi pembelajaran bagi mahasiswa agar lulusannya memiliki kompetensi yang diharapkan, tetapi juga memberikan manfaat bagi masyarakat dalam meningkatkan derajat kesehatannya.

CBE atau PBK tersebut sudah banyak diimplementasikan di fakultas-fakultas kedokteran di dunia dan di Indonesia (umumnya dikenal dengan istilah belajar lapangan). Lokasi PBK dapat di unit-unit layanan kesehatan primer maupun langsung di komunitas. PBK bagi mahasiswa profesi kesehatan bertujuan untuk memperdalam pengetahuan mereka tentang permasalahan kesehatan di komunitas, sekaligus untuk memfasilitasi masyarakat dalam meningkatkan derajat kesehatannya. Meskipun demikian banyak penelitian yang melaporkan bahwa PBK lebih banyak memberikan manfaat bagi mahasiswa dan institusi dibandingkan dengan manfaat yang didapatkan oleh masyarakat, di mana PBK tersebut diimplementasikan..$^{2-4}$ Beberapa penelitian tentang PBK melaporkan bahwa PBK memang memberikan manfaat bagi masyarakat, tetapi umumnya hanya bersifat sementara..$^{5-6} \mathrm{PBK}$ juga umumnya hanya berfokus pada pencapaian kompetensi mahasiswa secara umum tanpa memperhatikan kebutuhan pada kelompok masyarakat di mana PBK dilaksanakan, sehingga masyarakat seolah-olah menjadi obyek daripada subyek yang dapat terlibat secara langsung dan merasakan manfaat PBK.

Penanganan kesehatan masyarakat juga sangat kompleks dan seharusnya ditangani secara komprehensif dengan melibatkan berbagai profesi kesehatan. Oleh karena itu, mahasiswa dari profesi kesehatan juga perlu untuk mendapatkan pengalaman dalam bekerja sama antar profesi agar saling memahami dan menghargai peran masingmasing.

Saat ini semakin banyak institusi yang mengimplementasikan Interprofessional education (IPE). Umumnya pembelajaran tersebut hanya dilaksanakan di rumah sakit pendidikan yang bersifat top referral dan hasilnya memang menunjukkan adanya peningkatan pelayanan dan luaran dari pasien. ${ }^{7}$ Penelitian juga menunjukkan luaran positif yang lain, misalnya: peningkatan kualitas dalam 
pemberian pengobatan, keberlanjutan perawatan dan keselamatan pasien, ${ }^{8}$ sedangkan Thistlethwaite ${ }^{9}$ melaporkan bahwa IPE meningkatkan pengetahuan dan keterampilan kerjasama.

Saat ini strategi pembelajaran IPE masih sangat terbatas, umumnya difokuskan pada beberapa strategi yang spesifik misalnya seminar, workshops, dan simulasi. ${ }^{10}$ Oleh karena itu, institusi seharusnya juga memberikan pembelajaran tersebut dalam berbagai metode, tidak hanya di RS pendidikan saja yang umumnya bersifat top referral, tetapi juga bisa di layanan kesehatan primer maupun langsung di komunitas seperti halnya PBK. Diharapkan IPE yang dilakukan dengan berbagai setting lokasi akan memperkaya pengalaman mahasiswa dan juga lebih mendekatkan pada situasi yang sebenarnya saat mereka lulus nantinya.

Berdasarkan hal itu perlu dikembangkan suatu model PBK yang dapat memberikan manfaat yang nyata bagi masyarakat. Perlu dibuktikan bahwa PBK yang diimplementasikan secara terstruktur, berkelanjutan dan bersifat kolaborasi antar profesi kesehatan akan dapat memberikan tambahan nilai dalam mengatasi permasalahan kesehatan masyarakat di wilayah yang digunakan sebagai lokasi PBK.

Beberapa referensi PBK yang dilakukan dengan pendekatan IPE, umumnya masih merupakan percobaan dan hanya menggunakan sampel mahasiswa yang jumlahnya sedikit sehingga relatif mudah dikendalikan. ${ }^{11,12}$ Belum jelas apakah PBK dengan pendekatan IPE yang ditujukan untuk mahasiswa dengan jumlah besar akan memberikan dampak yang positif pula, mengingat kendala yang mungkin akan dihadapi misalnya dalam hal pengorganisasian tentunya akan merupakan tantangan tersendiri.

Penelitian ini masih berupa penelitian awal yang bertujuan untuk menghasilkan kombinasi model PBK-IPE yang berkelanjutan bagi mahasiswa profesi kesehatan dengan harapan agar mereka memiliki pengalaman berkolaborasi antar profesi kesehatan dalam mengatasi permasalahan kesehatan di masyarakat.

\section{METODE}

Penelitian kualitatif dengan analisis dokumen kurikulum pada 3 program studi (prodi) di Fakultas Kedokteran Universitas Diponegoro (FK Undip), yaitu: S1 Kedokteran, Keperawatan, dan Gizi dilakukan untuk menghasilkan draft model kombinasi PBK-IPE. Teori yang digunakan dalam menyusun draft model adalah teori reflective $\mathcal{E}$ experiential learning di mana terdapat campuran antara konten dan proses pembelajaran dan keseimbangan antara aktivitas pengalaman dengan konten atau teori, dan mahasiswa juga diharapkan dapat mengidentifikasi pengetahuan yang dibutuhkan dan mampu merefleksikan proses pembelajaran yang dialaminya. ${ }^{13}$

Tiga kali diskusi kelompok terfokus (DKT) dengan anggota kelompok yang terpisah, yaitu 1) Kepala Dinas Kesehatan Kota (DKK) dan stafnya; 2) Kepala Puskesmas, Tokoh Masyarakat dan kader; dan 3) Dosen-dosen dari 3 prodi. DKT dilakukan untuk mendapatkan masukan-masukan sekaligus memvalidasi draft model tersebut. Analisis dilakukan dengan cara melakukan koding pada transkrip DKT, dilanjutkan dengan mengkategorikan koding menjadi tema, dan memberi penjelasan pada tema berdasarkan data aslinya.

Penelitian ini telah mendapatkan persetujuan dari Komisi Etik Fakultas Kedokteran Undip No: 519/ EC/FK-RSDK/2015.

\section{HASIL DAN PEMBAHASAN}

Berdasarkan hasil evaluasi dokumen kurikulum dari ke 3 prodi, diperoleh keselarasan dalam hal waktu, kesiapan mahasiswa dan tujuan pembelajaran bagi mahasiswa semester 6. Oleh karena itu model PBKIPE dianggap sesuai bila diimplementasikan secara berkelanjutan selama mahasiswa belajar di semester 6.

Penanggung jawab dari program PBK-IPE maupun dosen pembimbing lapangan (DPL) terdiri dari dosen-dosen dari ke 3 prodi pula. Pengenalan program PBK-IPE pada calon DPL dan mahasiswa dilakukan sebelum implementasi dilaksanakan. Fakultas menyediakan sarana dan prasarana termasuk transportasi DPL, sedangkan transportasi 
mahasiswa ditanggung oleh mahasiswa sendiri. Dalam mengimplementasikan program ini dijalin kerja sama dengan Puskesmas Rowosari yang lokasinya cukup dekat dengan FK Undip, dan areanya memiliki jumlah populasi yang cukup luas didominasi oleh masyarakat dengan sosial ekonomi rendah. Adapun tema yang muncul pada hasil analisis DKT:

a. Sampling:

Keluarga yang dipilih untuk sampling pembelajaran mahasiswa adalah keluarga yang memiliki ibu hamil, dengan dasar pemikiran masih banyaknya ibu hamil dengan risiko tinggi dan masih tingginya angka kematian ibu hamil dan melahirkan di kota Semarang (diperkuat oleh data-data yang dikemukakan oleh kepala DKK dan kepala puskesmas)

b. Continuum of care:

Diharapkan dalam mengatasi permasalahan keluarga, mahasiswa juga mendapatkan pengalaman dalam menghadapi permasalahan kesehatan pada semua usia (continuum of care), sehingga bila dalam 1 keluarga ternyata jenis anggota keluarga masih kurang lengkap (minimal harus ada ibu hamil, balita, remaja, dan dewasa), maka mahasiswa harus menambah 1 keluarga lagi untuk melengkapinya.

c. Materi Pembekalan:

Materipembekalan meliputi penjelasan tentang IPE, alasan perlunya metode pembelajaran PBK-IPE, serta apa yang diharapkan dari PBKIPE dari sisi mahasiswa maupun masyarakat. Pemberian pembekalan materi lain adalah yang bersifat praktis, sehingga memudahkan mahasiswa dalam menerapkan ilmunya ketika beraktivitas di komunitas.

d. Jumlah mahasiswa/ tim:

Mengingat jumlah mahasiswa kedokteran yang lebih banyak dari ke 2 prodi lainnya, maka 1 kelompok kecil mahasiswa terdiri dari 1 atau 2 mahasiswa kedokteran, 1 keperawatan, dan 1 gizi kedokteran

e. Antisipasi kendala dalam implementasi:

Hal-hal yang bersifat praktis (agar ceklist untuk penilaian mahasiswa juga disertai rubrik) dan keselarasan jadwal mahasiswa dalam melakukan kunjungan keluarga. f. Berkelanjutan:

Program harus bersifat berkelanjutan (bukan one-shot intervention), agar tujuan peningkatan kesehatan masyarakat lebih dapat diukur. Aspek keberlanjutan ini dimasukkan dalam proses/aktivitas pembelajaran.

Berikut adalah Model PBK-IPE yang telah divalidasi:

\section{Who:}

a. PBK-IPE dikelola oleh Tim yang terdiri dari dosen ke 3 prodi.

b. Satu dosen Pembimbing lapangan (DPL) membimbing 3 tim kecil.

c. DPL berasal dari 3 prodi

d. Mahasiswa semester 6 membentuk tim kecil terdiri dari 1-2 mahasiswa kedokteran, 1 keperawatan, 1 gizi kedokteran

e. Kerja sama lintas sektoral dengan DKK dan Puskesmas

\section{What:}

a. Kompetensi yang diharapkan:

Mampu bekerja sama antar profesi kesehatan dalam mengidentifikasi dan mengatasi permasalahan kesehatan di tingkat keluarga

b. Tujuan umum pembelajaran:

- Memberi pengalaman pembelajaran dalam menangani permasalahan kesehatan keluarga secara berkolaborasi antar profesi kesehatan (kedokteran, keperawatan dan gizi kedokteran)

- Meningkatkan kesadaran mahasiswa akan peran dari masing-masing tenaga kesehatan dalam menangani permasalahan kesehatan keluarga

c. Tujuan khusus pembelajaran:

- Bekerja sama antar profesi kesehatan untuk mengidentifikasi permasalahan kesehatan keluarga

- Bekerja sama antar profesi kesehatan dalam memprioritaskan permasalahan kesehatan keluarga, serta menetapkan solusinya secara bersama dengan melibatkan partisipasi aktif keluarga dan kader

- Bekerja sama antar profesi kesehatan untuk mengimplementasikan solusi terhadap masalah kesehatan keluarga (intervensi dan 
monitoring) dengan melibatkan partisipasi aktif keluarga dan kader

d. Pedoman PBK-IPE disediakan bagi setiap mahasiswa untuk memudahkan mereka dalam menjalankan program. Pedoman berisi deskripsi singkat tentang alasan PBK-IPE, kompetensi yang diharapkan, tujuan pembelajaran, teknis di lapangan dan sistem penilaian. Pedoman dilengkapi dengan tabel rincian kegiatan serta ceklis penilaian mahasiswa yang dilengkapi rubrik

\section{Where:}

Lokasi pembelajaran: rumah dengan ibu hamil di area yang menjadi tanggung jawab Puskesmas di kota/ kabupaten Semarang.

\section{Why:}

Mengapa perlu model PBK-IPE?

a. Mahasiswa perlu mendapat pengalaman pembelajaran bersama antar profesi kesehatan dalam menghadapi permasalahan kesehatan di komunitas, yang dalam situasi nyata memang akan lebih baik bila diatasi secara terintegrasi dari berbagai disiplin ilmu kesehatan.

b. Mahasiswa diharapkan akan memahami dan menghargai peran masing-masing profesi kesehatan ketika harus bekerja sama dalam melakukan penatalaksanaan permasalahan kesehatan di komunitas, dan dalam hal ini masih di tingkat keluarga.

c. Kuliah Kerja Nyata yang dilakukan pada semester 7 atau 8 di FK Undip juga memberi pembelajaran lintas disiplin (tidak hanya profesi kesehatan) untuk membantu masyarakat mengatasi problemnya, dan sering kali masalah yang diangkat bukan permasalahan kesehatan, sehingga PBK-IPE khusus untuk mahasiswa profesi kesehatan memang diperlukan.

d. PBK-IPE diharapkan juga memberi nilai tambah untuk luaran yang lebih baik yang dapat dirasakan langsung oleh masyarakat.

e. Dosen mendapat kesempatan untuk melakukan penelitian bersama mahasiswa langsung di komunitas.

\section{How:}

a. Sebelum implementasi, dilakukan persamaan persepsi pada DPL yang berasal dari 3 prodi b. Pembekalan mahasiswa meliputi penjelasan:

- Alasan/ latar belakang dan tujuan PBK-IPE;

- Informasi tentang aktivitas yang harus dilakukan mahasiswa. Sebagai contoh bila ditemukan balita yang sulit makan dan kebutuhan gizi sehari-hari kurang, maka mahasiswa bisa bekerja sama melakukan intervensi promotif dan preventif dengan memberi edukasi tentang status gizi anak saat diperiksa, bagaimana tumbuh kembang anak dengan gizi yang baik atau kurang, jumlah kalori dan nutrisi yang dibutuhkan, variasi dan contoh-contoh menu makanan yang menarik bagi anak dan sesuai untuk pemenuhan kebutuhan nutrisinya.

- Sistem penilaian;

Pemberian materi praktis oleh dosen pakar dari ke 3 prodi untuk memudahkan mahasiswa dalam menjalankan program PBK-IPE.

c. Aktivitas mahasiswa adalah sebagai berikut:

- Bertemu kepala Puskesmas untuk mendapatkan penjelasan tentang situasi kesehatan masyarakat di area di bawah tanggung jawabnya

- Bekerja sama dengan kader dalam melakukan kunjungan rumah

- Memperkenalkan diri kepada keluarga dan menjelaskan tujuan kedatangan mereka

- Berkolaborasi antar profesi dalam melakukan identifikasi permasalahan kesehatan pada keluarga yang dikunjungi

- Melaporkan tentang permasalahan yang diidentifikasi pada DPL dan memformulasikan intervensi yang bersifat kolaborasi antar profesi untuk didiskusikan pada seminar I. Seminar dibagi menjadi beberapa ruang paralel.

- Bekerja sama untuk mengimplementasikan intervensi sesuai masukan para DPL dengan melibatkan peran aktif anggota keluarga dan bekerja sama dengan kader.

- Bekerja sama dalam memonitor dan mengevaluasi hasil intervensi.

- Bekerja sama dalam menyusun laporan dan mempresentasikan hasil intervensi pada seminar II 
- Laporan setiap kelompok kecil dikumpulkan di Bagian IKM FK Undip untuk dikompilasi oleh para DPL (merupakan poin tersendiri sebagai kegiatan DPL)

- Puskesmas dan DKK juga mendapat laporan tertulis yang sudah dikompilasi

d. Asesmen:

Pencapaian tujuan pembelajaran diases dengan menggunakan berbagai metode, yaitu: perilaku dan kedisiplinan; kerja sama (peer assessment), penilaian keluarga; laporan dan presentasi.

e. Luaran PBK-IPE:

Hasil kinerja mahasiswa terhadap permasalahan kesehatan yang teridentifikasi, intervensi yang telah dilakukan, dan kemungkinan adanya peningkatan dari indikator-indikator kesehatan, serta tindak lanjut dari pihak terkait.

f. Evaluasi program:

- Program dievaluasi dengan menyebarkan kuesioner dengan pertanyaan tertutup dan terbuka kepada mahasiswa sebelum dan sesudah implementasi (pre-post student's perceptions)

- Persepsi dan masukan dari Kepala Puskesmas, keluarga dan DPL terhadap program yang telah diimplementasikan dilakukan dengan metode wawancara

- Rapatkerja tim PBK-IPE untuk menganalisis hasil evaluasi program dan melakukan tindak lanjut.

Model PBK-IPE di FK Undip disepakati untuk diimplementasikan bagi mahasiswa semester 6 . Hal ini memiliki aspek keuntungan bila ditinjau dari kesiapan mahasiswa pada semester tersebut yang tentunya sudah memiliki pengetahuan dan keterampilan yang cukup memadai untuk diaplikasikan ke permasalahan kesehatan yang ada di komunitas. Meskipun demikian dalam model tersebut, dicantumkan pembekalan yang berupa penyegaran terhadap ilmu yang telah mereka dapatkan namun lebih bersifat praktis. Diharapkan dengan adanya pembekalan tersebut mahasiswa akan lebih percaya diri ketika berhubungan langsung dengan masyarakat.
Saat beraktivitas di masyarakat, mahasiswaditantang untuk mengaplikasikan pengetahuan yang telah didapatkan untuk melakukan penatalaksanaan masalah kesehatan yang ditemukan. Paparan terhadap berbagai permasalahan kesehatan di komunitas, sekaligus mendapatkan pengalaman bekerja dan belajar bersama antar profesi memberi kesempatan pada mahasiswa untuk mengidentifikasi dampak dari faktor sosial, ekonomi terhadap masalah kesehatan termasuk juga pengalaman tentang bagaimana mereka bisa berkontribusi untuk menghadapi permasalahan tersebut. Hal tersebut dapat mendorong mahasiswa agar tidak hanya fokus terhadap aktivitas pembelajaran, tetapi juga pada tujuan dan prinsip-prinsip yang menjadi latar belakang intervensi mereka. ${ }^{11}$

Shambaugh dan Magliaro ${ }^{14}$ menyatakan bahwa sebelum diimplementasikan, model pembelajaran harus dievaluasi untuk memutuskan masalah instruksional, kompetensi yang harus dicapai, dan konteks pembelajaran. Sebelum diaplikasikan, draft model ini juga telah dilakukan validasi sehingga aspek-aspek tersebut telah disepakati dan dicapai persetujuan bahwa model ini sudah layak untuk diimplementasikan. Dent dan Harden ${ }^{15}$ juga menyatakan bahwa dalam model pembelajaran terdapat komponen tujuan pembelajaran, konten, strategi pembelajaran, kesempatan belajar, evaluasi dan lingkungan belajar. Hasil DKT pada penelitian ini dapat dikatakan sudah dapat melengkapi hal-hal penting dalam komponen model pembelajaran, antara lain: latar belakang dan alasan perlunya program PBK-IPE, kompetensi yang diharapkan, tujuan pembelajaran, lingkungan tempat pembelajaran yang sesuai dengan tujuan pembelajaran, dan teknis pelaksanaan yang meliputi materi pembekalan, aktivitas pembelajaran dengan contoh-contohnya, serta sistem asesmen.

Model kombinasi PBK-IPE yang telah direncanakan dan divalidasi dalam penelitian ini juga sudah disesuaikan dengan hasil penelitian yang dilakukan oleh Kristina et al ${ }^{16}$ yang menyimpulkan bahwa implementasi program PBK yang melibatkan peran aktif masyarakat sangat dihargai baik oleh mahasiswa maupun masyarakat sendiri. Oleh karena itu, dalam model ini pada aspek aktivitas 
mahasiswa telah dituliskan secara eksplisit bahwa mahasiswa harus melibatkan peran aktif dari keluarga dan kader dalam melakukan intervensi mereka. Perlunya integrasi dari program kesehatan pemerintah terkait dengan permasalahan yang mungkin akan teridentifikasi oleh mahasiswa, ${ }^{17}$ juga telah terakomodasi dalam pengembangan model ini yaitu dengan melibatkan DKK dan puskesmas sehingga dicapai kesepakatan untuk menggunakan keluarga yang memiliki ibu hamil sebagai tempat pembelajaran.

Suatu Pilot study implementasi IPE dengan mengirimkan mahasiswa kedokteran dan farmasi untuk mengikuti praktik dokter keluarga, dilanjutkan dengan presentasi dan diskusi tentang pengalaman yang mereka dapatkan terbukti dapat membantu mahasiswa untuk lebih memahami nilai dari efektivitas kinerja tim yang bersifat interprofesi dan meningkatkan respons mereka terhadap masalah kesehatan di komunitas, sehingga mereka menyimpulkan bahwa IPE yang diimplementasikan di komunitas cukup relevan, memungkinkan untuk dilakukan (visible), dan benar-benar sangat diperlukan. ${ }^{12}$

PBK-IPE merupakan program yang relatif baru untuk fakultas kedokteran sehingga sebelum diimplementasikan diperlukan masukan dari beberapa pihak. Dalam penelitian ini hampir semua pihak yang terlibat dalam implementasi telah dilibatkan, yaitu: DKK, puskesmas, tokoh masyarakat, kader dan dosen pembimbing. Oleh karena itu, DKT yang dilakukan untuk validasi draft model ini, bisa dikatakan sebagai proses evaluasi dari suatu perencanaan pembelajaran, karena telah menghasilkan model PBK-IPE dengan banyak kesepakatan-kesepakatan dengan harapan hasilnya akan memuaskan setelah diimplementasikan.

Mahasiswa merupakan pihak yang terlibat dalam pelaksanaan model ini, meskipun demikian penelitian ini belum melibatkan mahasiswa sebagai responden sehingga kemungkinan model tersebut masih memiliki kelemahan, misalnya dari aspek keselarasan waktu untuk kunjungan rumah, di mana hal ini yang juga telah diantisipasi oleh salah satu responden (dosen) pada saat DKT. Oleh karena itu, dalam model telah dicantumkan bahwa mahasiswa harus bekerja sama dengan kader dalam melakukan kunjungan rumah karena dianggap kader lebih mengerti tentang situasi dan kondisi di lingkungannya, lebih mengenal satu-persatu keluarga yang akan dijadikan sasaran kunjungan dan juga dapat menjembatani aspek keselarasan waktu yang disetujui oleh pemilik rumah untuk dikunjungi oleh mahasiswa. Mudahnya komunikasi dengan alat bantu elektronik tentunya akan mempermudah urusan ini. Meskipun demikian, halhal tak terduga akan bisa terjadi mengingat bahwa IPE yang akan diimplementasikan langsung di komunitas ini tentunya memiliki sisi yang unik dan tantangan yang cukup berat dibandingkan dengan model pembelajaran IPE di RS maupun di kelas yang relatif mudah dikendalikan. Oleh karena itu, dalam perencanaan untuk mengevaluasi program, telah dicantumkan bahwa mahasiswa, keluarga, dan pihak puskesmas akan dimintai pendapat dan masukannya.

Suatu model pembelajaran perlu divalidasi internal dan eksternal. Validasi internal terhadap draft model telah dilakukan, tetapi validasi eksternal masih perlu dilakukan untuk mendapatkan masukan-masukan setelah diimplementasikan. Validasi eksternal juga dapat dilakukan dengan cara meminta masukan dari pakar pendidikan kedokteran dari institusi lain, maupun dosen yang terbiasa dengan implementasi pembelajaran di lapangan (komunitas).

Model yang dikembangkan oleh penelitian ini masih bersifat lokal sehingga masih perlu dilakukan penelitian-penelitian berikutnya yang bersifat lebih luas (regional/ nasional) dengan melibatkan institusi-institusi lain, sehingga dapat digunakan sebagai model pada institusi yang lebih luas. Di samping itu, keberhasilan model ini dalam usaha untuk meningkatkan derajat kesehatan masyarakat di tingkat keluarga juga masih perlu dibuktikan setelah diimplementasikan secara berkelanjutan di lokasi yang sama.

\section{KESIMPULAN}

Model PBK-IPE disarankan untuk diimplementasikan bagi mahasiswa yang telah memiliki kompetensi yang cukup untuk diaplikasikan di masyarakat. Disarankan agar model 
ini juga dapat diterapkan untuk program studi kesehatan lain dalam program pembelajaran yang melibatkan komunitas. Kajian dan validasi lanjut terhadap model masih perlu dilakukan setelah diimplementasikan.

\section{UCAPAN TERIMA KASIH}

Terima kasih ditujukan kepada Kepala DKK Semarang (dr. Widoyono, MPH) dan Kepala Puskesmas Rowosari (Heri Wibowo, SKM, MKes) yang telah memfasilitasi dan memberi masukan untuk program ini.

\section{DAFTAR PUSTAKA}

1. Departemen Kesehatan Republik Indonesia. Sistem Kesehatan Nasional tahun 2004. Jakarta; 2004.

2. Olm-Shipman C, Reed VA, Jernstedt GC. Teaching children about health, Part II: The effect of an academic-community partnership on medical students' communication skills. Educ for Health. 2003;16(3):339-47.

3. Williams RL, Reid SJ, Myeni C, Pitt L, Solarsh G. Practical skills and valued community outcomes: The next step in community-based education. Med Educ. 1999; 33(10):730-7.

4. Kristina TN, Majoor GD, Van der Vleuten CPM Does CBE come close to what it should be? A case study from the developing world. Evaluating a programme in action against objectives on paper. Educ for Health. 2005;18(2):194-208.

5. Kazemi D, Behan J, Boniauto M. Improving teaching strategies in an undergraduate community health nursing $(\mathrm{CHN})$ program: Implementation of a service-learning preceptor program. Nurse Educ Today. 2011;31(6):547-52.

6. Magzoub M, Schmidt H, Ilyas M, Lewis J. Impact of community-based educational programme (1): Effects on the community. In: Schmidt HG, Magzoub M, Felleti G, Nooman Z, Vluggen P, editors. Handbook of Community-Based Education: Theory and Practices. First ed. Maastricht: Network Publications;2000.
7. Centre for Interprofessional Education at the University of Toronto. Interprofessional education to provide practice-based health professionals at affiliated hospitals and community clinical placements. http//:www. TorontoUniv. AcadHealth Sciences. Network;2014(Retrieve:2January 2014).

8. Paradis E, Reeves S. Key trends in interprofessional research: A macrosociological analysis from 1970 to 2010. Journal of Interprofessional Care. 2013;27(2):113-122.

9. Thistlethwaite J. Interprofessional education: A review of context, learning and the research agenda. Medical Education. 2012;46(1):58-70.

10. Reeves S, Goldman J, Gilbert J, Tepper J, Silver I, Suter E, Zwarenstein M. A scoping review to improve conceptual clarity of interprofessional interventions. Journal of Interprofessional Care. 2011;25(3):167-174.

11. Stewart V, Betts $\mathrm{H}$, Chee $\mathrm{P}$, and Ingamells $\mathrm{A}$. Interprofessional Learning: Health and Allied Health Students in a Community Context. Adv in Social Work \& Welfare Educ. 2015;17(2):70-85.

12. Hasnain M, Koronkowski MJ, Kondratowicz DM, Goliak KL. Training Future Health Providers to Care for the Underserved: A Pilot Interprofessional Experience. Education for Health. 2012; 25(3):204-7

13. Moon JA. A Handbook of Reflective \& Experiential Learning. Theory \& Practice. London \& New York. Taylor \& Fancis; 2004.

14. Shambaugh RN, Magliaro SG. Mastering the possibilities: A proses approach to instructional design. Massachusetts: Allyn and Bacon;1997.

15. Dent JA, Harden RM. A practical guide for medical teachers. $4^{\text {rd }}$ ed. Elsevier Churchill Livingstone; 2013.

16. Kristina TN, Majoor GD, Van der Vleuten CPM. Does CBE come close to what it should be? A case study from the developing world. Student's opinion. Educ for Health.2006;19(2):179-188.

17. Kristina TN. Effectiveness of Continuous Community Based Education Program: Malnutrition Identification Followed by Tuberculosis Screening. Med Medika Ind. 2008;42:111-5. 